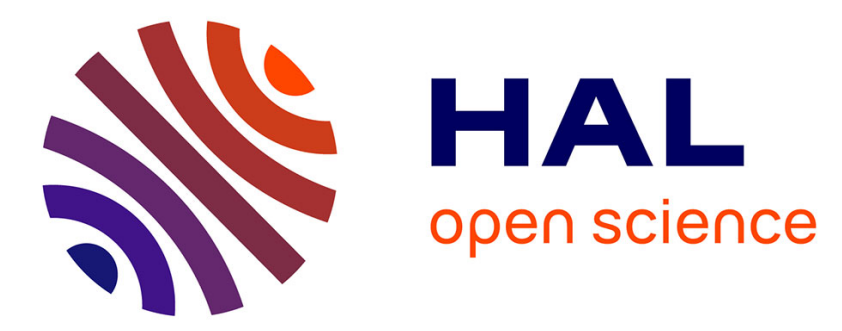

\title{
Evidence-Based Professional Development of Science Teachers in Two Countries
}

\author{
Christine Harrison, Avi Hofstein, Bat-Sheva Eylon, Shirley Simon
}

\section{To cite this version:}

Christine Harrison, Avi Hofstein, Bat-Sheva Eylon, Shirley Simon. Evidence-Based Professional Development of Science Teachers in Two Countries. International Journal of Science Education, 2008, 30 (05), pp.577-591. 10.1080/09500690701854832 . hal-00513364

\section{HAL Id: hal-00513364 \\ https://hal.science/hal-00513364}

Submitted on 1 Sep 2010

HAL is a multi-disciplinary open access archive for the deposit and dissemination of scientific research documents, whether they are published or not. The documents may come from teaching and research institutions in France or abroad, or from public or private research centers.
L'archive ouverte pluridisciplinaire HAL, est destinée au dépôt et à la diffusion de documents scientifiques de niveau recherche, publiés ou non, émanant des établissements d'enseignement et de recherche français ou étrangers, des laboratoires publics ou privés. 


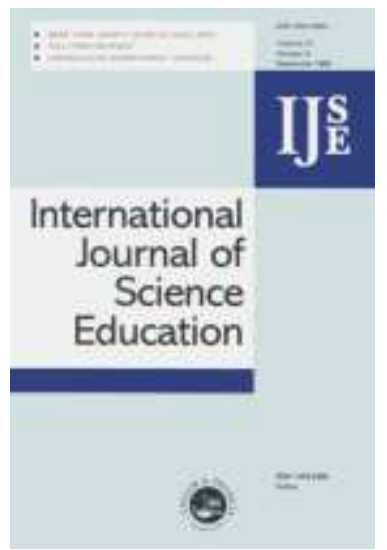

\section{Evidence-Based Professional Development of Science Teachers in Two Countries}

\begin{tabular}{|r|l|}
\hline Journal: & International Journal of Science Education \\
\hline Manuscript ID: & TSED-2007-0143.R1 \\
\hline Manuscript Type: & Special Issue Research Paper \\
\hline Keywords: & teacher development, science education \\
\hline Keywords (user): & \\
\hline \multicolumn{2}{|l}{} \\
\hline
\end{tabular}

\section{S ScholaroNE \\ Manuscript Central}




\title{
Evidence-Based Professional Development of Science Teachers in Two Countries
}

\begin{abstract}
The focus of this collaborative research project of King's College London, and the Weizmann Institute, Israel. project is on investigating the ways in which teachers can demonstrate accomplished teaching in a specific domain of science and on the teacher learning that is generated through continuing professional development programs (CPD) that lead towards such practice. The interest lies in what processes and inputs are required to help secondary school science teachers develop expertise in a specific aspect of science teaching. 'It focuses on the design of the CPD programmes and examines the importance of an evidence-based approach through portfolioconstruction in which professional dialogue pathes the way for teacher learning. The set of papers highlight the need to set professional challenge while tailoring CPD to teachers' needs to create the environment in which teachers can advance and transform their practice. The cross-culture perspective added to the richness of the development and enabled the researchers to examine which aspects were fundamental to the design by considering similarities and differences between the domains.
\end{abstract}




\section{Rationale and theoretical background}

The studies described in this set of papers were carried out as part of a three year cycle of collaborative research and development activities conducted by King's College, London UK and the Weizmann Institute of Science, Israel. The project presented in this special issue is based on the premise that in order to advance the educational system and improve the practice of teachers, it is essential to promote the professionalism of teachers beyond initial training through Continuing Professional Development (CPD). More specifically, our interest centered on what processes and inputs are required to help secondary school science teachers develop expertise in specific aspects of science teaching and how engaging with these processes helped teachers reflect on, develop and learn about their pedagogy.

The overarching goal has been to design evidence-based CPD programmes for developing accomplished teaching in science. By this we mean CPD programmes which require the teacher participants to take part in a professional development programme that requires them to seek and identify evidence of practice in their own classrooms. The focus for this evidence-based CPD approach is the process of collection, analysis and reflection on evidence arising from classrooms and how this provides the impetus and motivation for teachers to transform their practice.

The following six domains of science education were chosen for developing these programmes:

1. Scientific enquiry with investigations,

2. Scientific discourse and argumentation, 
3. Classroom assessment

4. Knowledge integration in physics,

5. Learning skills in science,

6. Inquiry in the chemistry laboratory.

These domains are not intended to provide a comprehensive description of expertise in science teaching but rather they are illustrative of some of the important qualities needed by an accomplished teacher of science. These six domains of science education were each used as a vehicle to enhance teacher learning through engaging in CPD programmes and producing an evidence-based portfolio. The CPD programmes were designed to both increase teachers' knowledge of specific domains and help them reflect on how such ideas can be developed and interpreted into pedagogy. This included helping teachers experiment and reflect on how the new ideas could be developed and integrated into classroom practice. It also provided opportunities for them to understand the utility of using evidence as part of their regular cycle of reflection and development on practice.

The first three domains were developed in the UK and the others in Israel. It was assumed that the collaborative effort between two nations that possess different educational structure and philosophy, as well as different cultural beliefs and practices of the students, would provide rich and versatile information regarding the dynamics and constraints of the model. The collaboration also encouraged the CPD developers to clarify and explain the reasoning behind their decisions and actions within the individual CPD programmes with colleagues who were familiar with the research literature and confident in their own domain, but unfamiliar with the ways teaching 
ideas were interpreted and implemented in the other country. This helped us question the status quo and seek new possibilities and alternative solutions instead of simply accepting what was already in place or follow trends that had previously directed particular teaching and CPD approaches. It also provided us with a broader and richer base on which to focus development of the evidence-based aspect of the CPD work within the context of our specific domains. The cross-country liaison encouraged us to question more carefully each aspect of the CPD programme. The culture of CPD and teacher learning was different in the two countries and so selection of approaches, which we might have previously made unthinkingly, now had to be explained to our counterpart developers. This caused us to reflect more thoroughly than we might have done if the project had only been placed in one country. Equally, new ideas from the other country provided us with a greater choice of possibilities for the CPD design at all stages in the research programme.

This collaborative approach helped both with the pragmatics of the developmental part of the work while informing the theoretical thinking underpinning the project. For example, one Israeli researcher and one UK researcher worked together to review the research on accomplished practice and produce a working paper to support the other domains. Another pair from the two countries exchanged ideas about the preparation and use of the portfolio, which helped all six domains find better ways of supporting their teachers in preparing the portfolios. A further pair of researchers, from Israel and the UK, compared the response by their teachers to the first few CPD sessions and their findings influenced the other domains in the design of their CPD programmes. 
This set of papers describes and offers insights into the CPD programmes that have been developed in these science learning domains. The papers report on selected aspects of research on the implementation process and the professional development and practice of teachers. They provide an opening into investigating the role of professional dialogue and the development of teacher learning communities within the CPD arena and draw on an extensive research base (Shulman (1992), Bell \& Gilbert (1996), Hoban (2002), Loucks-Horsley et al (2003) which puts teacher learning at the centre of the CPD agenda.

Within a large project, where researchers have specific foci for their research, it is not unusual to have central tenets for research which become moulded and adapted within the smaller units of the research. For example, the paper by Shirley Simon and Susan Johnson focuses on how the final portfolios demonstrate teachers' progression towards accomplishment, while that by the Knowledge Integration team, led by BatSheva Eylon, centres on the changing categories of teacher talk in the early teacher meetings compared to later ones. For this reason, we lay out the main areas of the research programme below, while recognizing that there is variation of these in some of the domains and refinement of specific ideas within the individual papers. Some of the central research questions that fashioned our approach were:

What are the qualities of an "accomplished" teacher of science?

What evidence can be collected by teachers to explore the teaching and learning processes within their own classrooms?

How can the collection of evidence provide a focus for reflection within a programme of continuing professional development for science teachers? 
This set of papers reports mainly on the last research question although some details relating to the first three questions will, by necessity, be reported also. This paper provides the backdrop for the papers that follow. It begins by considering the evidence-based approach and what we mean by accomplished teaching. It then focuses on the design of the evidence-based CPD programmes and goes on to explore the use that portfolios were put to as part of this process. The developmental aim was to develop, adapt and hone a CPD programme in each domain and to produce a set of materials that would help CPD providers introduce similar programmes in the future. The research aim was to explore how involvement within an evidence-based CPD programme affected teacher learning and practice for that domain.

This paper provides the backdrop and rationale for the papers that follow. It begins by considering the evidence-based approach and what we mean by accomplished teaching. It then focuses on the design of the evidence-based CPD programmes, outlines the main research tools and analyses and goes on to explore the use that portfolios were put to as part of this process.

\section{The "evidence-based" approach}

Effective CPD needs to provide an opportunity for teacher reflection and learning about how new practices can be evolved or moulded from existing classroom practice. Teachers need to familiarize themselves with new ideas and also understand the implications for themselves as teachers and for their learners in the classroom before they adopt and adapt them. If the new approach differs greatly from their previous practice, this involves them reshaping their own beliefs regarding science teaching and learning. It thus involves both considering core principles and issues as well as contextualizing these in developing practice and approaches. The challenge comes 
when teachers return to their schools, where their ideas developed during the CPD sessions might falter outside the supportive climate of the Teacher Meetings. This is particularly so where the innovations introduced differ markedly from the 'normal' practice within the school and, as such, challenge the "dominant structures and values that hold habits in place” (Ruddock,1991, pp.27-28).

Conventional methods of conducting CPD have usually been too short and occasional to foster change in teacher classroom practice (Loucks-Horsley, Hewson, Love and Stiles 1998). Research highlights some important features that characterize effective CPD programmes (e.g., Ball and Cohen, 1999; Loucks-Horsley, Hewson, Love and Stiles, 1998; Bell and Gilbert, 1998; Kennedy, 1998; Marx, Freeman, Krajick and Blumenfeld, 1998; Putnam and Borko, 2000; Roth, 2002; Borko, 2004).:

- Engaging teachers in collaborative long-term inquiries into teaching practice and student learning.

- Situating these inquiries into problem-based contexts that place content as central and integrated with pedagogical issues.

- Enabling teachers to see such issues as embedded in real classroom contexts through reflections and discussions of each others' teaching and/or examination of students' work.

- Focusing on the specific content or curriculum teachers will be implementing such that teachers are given time to work out what and how they need to adapt what they already do.

Effective professional development needs to provide an opportunity for teacher reflection and learning about how new practices can be evolved or shaped from 
existing classroom practice. This is not a simple task in that it requires teachers to reexamine what they do and how they might do it differently. In addition, the attainment of complex learning goals in science by students, such as the ones targeted in the domains of the present project, demand significant change in teachers' roles.

The CPD programmes developed in this project employ an "evidence-based" approach to support collaborative inquiries in the teachers' own classrooms. By the term "evidence" we mean a collection of artefacts in a particular science learning domain that show teacher's work and students' learning, combined with written commentaries that explain the role of the artefacts within the learning context. Ball (2004) refers to "harnessing" recorded teachers' experience as a means for teachers' learning individually and collectively and creating shared professional knowledge. Such records of practice (evidence) enable teachers to examine their own instructional strategies and students' learning alongside their previous practice and those of their colleagues. The preparation of the evidence, and the reflection that follows it, can help teachers gain insights, evaluate goals, better understand the relationship between components of practice or events, and view them within a broader cultural, moral, and professional perspectives. Namely, the evidence and the activities associated with its processing foster the creation of a community of practice (Lave and Wenger, 1991). The process of collecting and explaining and justifying these evidence sources therefore helps in enhancing teachers' development towards accomplishment in their practice.

Accomplished Teaching 
Schulman \& Schulman (2004, pp.259) stipulate that " an accomplished teacher is a member of a professional community who is ready, willing, and able to learn from his or her teaching experiences". They go on to argue that the features of teacher development and so a necessary part of what a CPD programme should provide are Vision, Motivation, Understanding, Practice, Reflection and Community. While we whole-heartedly agreed that these were necessary aspects to aid teacher learning, our feeling was that the evidence-based approach would provide the means by which the focus, practice and reflection could drive the understanding through the professional dialogue that it engendered within the CPD Teacher Meetings. In other words, the evidence-based approach formed the catalyst for high levels of socio-cultural interaction between the teachers on the CPD programme so that they were able to overcome the hurdles of implementing these new practices (Cuban, 1998) on their return to their schools

Realizing the complexity of skills involved in collecting and using evidence, the CPD programmes involve activities designed to directly develop teachers' skills in collecting, sharing and reflecting on evidence. These activities also provide an opportunity for the CPD provider to offer guidance, tools and support in this endeavour. The development of these evidence related skills is intertwined with the development of expertise in a particular domain of science learning and so, while there was commonality in approach within the six science domains, there was also, by necessity, variation in these activities. Some of the programmes offered new approaches to the teachers, such as Knowledge Integration in Physics for the Israeli teachers, while others built on existing practice, such as the Classroom Assessment programme, which helped UK teachers concentrate on aspects of science teaching that was already part of their existing repertoire and look at how they might improve it. 
The major goal of the CPD models produced in this project has been to promote expert teaching. Both the UK and Israeli teachers preferred to use the term accomplished rather than expert teaching. Their argument arose from the idea that experience as well as knowledge and understanding of practice was a necessary part of teacher development. They felt that the term 'expert' suggested that someone had researched and studied teaching, while they considered their improvements in practice resulted more from their gradual development through experience in the classroom. They believed that as they honed their classroom practice they grew towards accomplishment rather than becoming expert within a domain.

Accomplished teaching of science can be defined in terms of the knowledge which teachers use in their teaching (Guskey and Huberman 1995; Hewson and Hewson 1988; Magnusson, Krajcik and Borko. 1999; Shulman 1987). This knowledge has been categorised as general pedagogical knowledge, subject-matter knowledge, and pedagogical content knowledge (Borko and Putnam, 1996). The descriptions of accomplished teaching in each domain were firmly grounded in both extensive reviews of the literature and in expert teachers' classroom practices. Our work is concerned with the qualities that distinguish an accomplished teacher from a simply competent one and how the CPD programmes can help teachers progress towards accomplished practice in each of the domains. This involves the teacher in developing both their subject matter knowledge and pedagogical content knowledge. Subject matter knowledge includes teacher's knowledge of facts, concepts and procedures within a particular domain, such as scientific enquiry.

Pedagogical content knowledge is concerned with the teaching and learning of a particular domain: knowing how students learn within that domain, knowing their 
common misconceptions and the particular difficulties and challenges of that domain, and being able to apply this knowledge to teaching and learning within that particular domain (Shulman, 1987). Another aspect of accomplished teaching termed "scholarship of teaching" is proposed by Hutchings and Shulman (1999). They suggest that besides excellent teaching, teachers should be able to articulate their teaching actions and thinking in a way that others can learn from it and should be available for community discourse and study. They also claim that this public feature of teaching improved teachers' learning and performance through reflection and professional discourse.

We assume that in order to increase the effectiveness of the CPD programmes, it is important that the teachers share what is meant by accomplished practice in the particular domain. The shared vision and its explication can provide a sense of direction, and guide the teachers to focus their efforts towards the central goals of accomplished teaching in the particular domain. Indeed, teachers commented that agreed standards to define accomplished teaching in specific domains were useful as tools to improve competence and against which to judge competence as shown in evidence collected from the classroom. For us as CPD providers the definitions of accomplished teaching within each domain have been an integral part of our planning of new CPD programmes and as tools to help teachers to map progress and decide on next steps towards accomplished teaching.

It should be noted that coming to agreement about accomplished teaching in each domain was grounded in different cultural contexts, different countries and to some extent with teachers of students of different ages. Competences that might be 
considered to be basic in one cultural context, may be considered to be advanced in another and vice versa. Although there are many commonalities between science teaching in the UK and in Israel, there are also differences. It should not, therefore, be surprising if there are differences between say the accomplished teaching of scientific enquiry in the UK and the accomplished teaching of inquiry in Israel. What would be surprising, however, would be if there were not many more commonalities in the descriptions.

\section{The Continuing Professional Development Programmes}

The project was conducted over the period of three years (2002-2005). The project was carried out in collaboration with teachers to bridge between theory and practice and to increase the validity and feasibility of the proposed programmes.

The project consisted of three phases. In each phase a new cohort of teachers undertook the CPD programmes:

- Phase 1- the CPD programmes were designed and piloted, either using teachers who had some expertise in the domain or, in the case of the Israelis, leading (exemplary) teachers $(\mathrm{N}=32)$.

- Phase 2 -the CPD programmes were trialed and evaluated by experienced teachers who had only a small amount of knowledge of the specific domain $(\mathrm{N}=38)$.

- Phase 3 - the CPD programmes were refined and then trialed again by teachers with minimal knowledge of the domain $(\mathrm{N}=34)$. 
Each of the CPD programmes involved the teachers in some 30-40 hours of teacher meetings. The organization of the CPD programmes varied across the domains to try and fit in with preferred timings for both the teachers and the researchers. Typically, the UK programmes were divided into six to ten whole or halfday sessions over the course of two school terms, with periods between teacher meetings utilized by the teachers to explore and develop ideas in their own classrooms. In Israel, the programmes generally began with an intensive 2-3 days of CPD, where the teachers became fully immersed in the ideas and practices of the specific domain. This was then followed by teacher meetings at roughly monthly intervals over the course of eight to ten months.

Each CPD programme had some specific characteristics that were shaped by previous CPD programmes that the developers had been involved in and each was also influenced by the pedagogical content knowledge of the specific domain, in that the CPD providers attempted to model some aspects of the approach (Hogan and Berkowitz, 2000). However, several features were common to all domains. All the programmes dealt with ways to implement the pedagogic approaches using concrete instances derived from classroom practice. This provided the impetus for professional dialogue as the teachers came to recognize particular techniques and to evaluate how these might be incorporated into their existing teaching repertoire. Teachers were then able to plan classroom activities and work out, with support from the CPD providers and their colleagues on the CPD programme, how they might capture evidence of their changing practice. 
In all the domains, the first few attempts at collecting evidence of practice were relatively prescriptive in nature, but as the teachers became more adept at collecting evidence and gained confidence and competence within the specific domain they began to select from a wider range of evidence sources. The teachers thus increased their autonomy in line with their development towards accomplished teaching.

The goals and approach of the CPD programmes were designed to allow for this evolution of practice and understanding in that the activities and sessions fostered teacher learning in the particular science domains by:

- Helping teachers become aware of the need to stimulate and support students in learning activities in the domain

- Exposing teachers to central ideas in the domain and a variety of instructional activities

- Encouraging teachers to customise activities in the domain to their needs and implement them effectively

- Providing guidance to a wide range of teachers enabling them to evidence their practice and improve their knowledge and skills

- Guiding teachers in collecting evidence of accomplished teaching

- Facilitating meetings where teachers could discuss and reflect on the documented practice, with presenting artefacts as evidence that demonstrated their changing practice

- Helping teachers select documented evidence to illustrate their development in their portfolio 
The goals were achieved in each of the domains by ensuring that the CPD programmes included the following elements: setting goals, learning from examples by reflection on the evidences of practice that were produced, customising and developing ownership of the next steps towards accomplishment. There were, however, a range of ways in which this process was carried out in the different domains as described in the different papers. Towards the end of each CPD programme, the teachers submitted a portfolio that documented evidence to demonstrate their progress towards accomplished teaching in one of the six domains. Outlines of the CPD programmes have been published (2007) and more detailed information can be located on poecpd.org.uk.

Use of the Portfolio

An essential feature of each programme was the construction of an individual portfolio by participating teachers, which would include evidence of how teaching strategies had been implemented and how teachers reflected on their practice. In each domain, the teachers were provided with expert input based on previous research that helped to guide the construction of teachers' portfolios. In addition, sharing and discussing portfolio entries with peers in the programme was perceived as a means of enhancing reflective practice through collaborative analysis of evidence.

Previous research that supports the potential of portfolios as a tool for enhancing learning and development has been widely reviewed and documented (Lyons, 1998; Dinham \& Scott, 2003; Orland-Barak, 2005). Yet portfolios have been defined in different ways depending on their purpose, for example, for certification, selection, appraisal or promotion, as well as for professional development (Klenowski, 2002). 
The portfolio used for CPD purposes usually involves the selection of materials that provide evidence for critical examination of teaching and learning practices. The emphasis in portfolio development could be on the process of construction or on the quality of the product, and there are tensions between these two purposes that should inform the use of portfolios for CPD. If the product is the goal then this suggests a summative approach, where comparison might be made between the finished portfolios, which in turn compares the teachers' competence within the group. Such an emphasis is hardly conducive to collaborative endeavour. It could also render the CPD provider the role of judge, and hence conflict with their role as facilitator and guide. If a more formative approach was to be undertaken, then it seemed important that the emphasis of the professional development effort should centre on the process of constructing the portfolio rather than the finished product. Linked to this was the necessity of creating a professional development environment where teachers were open to sharing their ideas, as well as seeking and offering support amongst their peers. The CPD programmes of the King's -Weizmann project sought to incorporate substantive conversation and collaboration between participants as they engaged in the process of constructing individual portfolios to foster a collaborative professional development environment.

\section{Research Tools and Analyses}

Throughout the three year project, data were collected both by the teachers involved in the CPD programme and the researchers. Video or audiorecordings were made of each $\mathrm{CPD}$ teacher meeting and data were also collected from interviews, classroom observations, classroom videos and questionnaires. The completed portfolios also provided a rich data source. 
Permission was sought from the teachers to use the work they produced for their portfolio entries as well as that from utterances at teacher meetings and the interview and classroom observation data. Anonymity of teachers and schools was ensured by use of pseudonyms on all documentation and by ensuring safe and confidential storage of all project artifacts and data.

The approach to analysis followed a similar cycle of processes within each of the research teams for the six science domains. Interviews were transcribed, open-coded by pairs of researchers using a grounded-theory approach (Stauss and Corbin, 1994) from which emerging themes were examined, tested for validity across data sets by blind comparisons and finally used to write detailed vignettes or case studies of each of the teachers.

For the blind comparisons, a sample of at least half the interviews was selected randomly. These were independently coded and then analyses compared. Coding accuracy was improved by writing theme code desciptors and, in some cases, further coding through paired discussion and this resulted in raising coding agreement rate above $70 \%$.

Audio and videotapes of the CPD teacher meetings were not transcribed always in full. Instead, they were listened to and summarized independently by at least two researchers in each domain. This decision was partly due to the large amount of such data and also because some of the quality, particularly on the audiotapes made it difficult to hear every word spoken. Critical incidents 
or noteworthy sections were identified and these were then transcribed and added to the summaries. In some domains where the main data source for a particular line of investigation involved teacher talk, researchers elected to do full transcriptions and analyses of videotapes. This is evident in the Knowledge Integration paper in this set.

Classroom observations were recorded through field notes and video. The video was summarized and critical incidents and noteworthy sections added in a similar process to that used for the recordings of the teacher meetings.

Coding of the teacher meeting summaries and interviews resulted in a number of themes emerging. Analysis has involved cross-referencing and triangulation of themes in data sets from audio- and video-recordings of the teacher discussions in the CPD sessions, teacher interviews and the portfolio documents and has involved comparisons of data sets across the domains.

Discussion of findings

This introductory paper is intended to map out the ground for the papers that follow where more specific findings will be reported. The findings that we report are therefore in more general terms across the six domains of the project and describe the constraints and affordances that we encountered.

Finding 1: The CPD programmes provided opportunities for teacher reflection and learning. 
I really enjoyed turning up for the CPD sessions. The activities were good for getting you thinking and working with like-minded teachers was a real bonus. You were prepared to have a go at new ways of working, to reflect on what happened and refine it so that it worked every time. I think all CPD should be like this.

Lily, Final interview, June 2005

There are many challenges for developing effective CPD programmes in that such endeavours need to provide regular and sustained opportunity for teacher reflection and learning. The 1988 review of CPD effectiveness (Joyce \& Showers) indicated that programmes needed to be centred on classroom practice so that new practices could be evolved and moulded from existing practice. Our approach was a move away from the classic Joyce and Showers coaching approach, where an 'expert' supports the development in the teacher's own classroom. Instead, we asked teachers to recognise, collect and bring evidence from their own classrooms for analysis and reflection in teacher meetings. This therefore placed a greater responsibility on the individual teachers within the developmental process and provided an extra layer of reflection and advice from their peers and this occurred through the professional dialogue at the teacher meetings. This not only reduced the dependency on the expert coach, but helped foster a teacher learning community in which collaborative endeavour provided both the support and impetus for teachers to take risks once they returned to their own classrooms (Hoban, 2000).

One noteworthy point was the positive attitudes and satisfaction of teachers with the programmes. Teachers enhanced their acquaintance with the domain, their pedagogical content knowledge, their practical teaching knowledge and their sensitivity to students' understanding and progress. The socio-cultural practice that 
the teachers engaged in through the CPD programmes played an essential part in aiding teacher learning. Teachers appreciated getting constructive feedback from the researchers, from their peers and from experienced teachers for that domain both about the reported activities and about the collection of evidence. It should be noted that in the beginning of the CPD program, teachers had difficulties in carrying out the evidence-based approach. However, over the course of the programmes we observed that it became a powerful means in creating the community of practice. Teachers felt free to share with their peers' achievements and difficulties and to use these opportunities as vehicles for professional growth.

Finding 2: The teachers initially found the evidence-based approach to CPD difficult. They spoke about time constraints and possible problems of acceptability of new approaches with colleagues in their schools. In later interviews, many had either gained confidence to pursue their individual developmental goals or recognised that the concerns they had were not as critical as they had first envisaged, but rather were ways of protecting themselves in case they failed to make the changes they wanted in their classrooms.

Looking back, it hasn't been half as difficult as I imagined it would be to bring about these changes in my classroom. I thought at the start I want to do this but what if I can't find the time to do it. The idea of having to bring evidence was scary but, in reality, its been the thing that has helped me see what I am doing and not doing to help my students learn.

Amina, final interview June 2004 
The difficulties that many teachers face when introduced to new approaches in the classroom is how to work these new ideas into their existing practice so that a different overall practice emerges (Priestly \& Sime, 2005). This is not a simple task as it requires the teacher to understand the implications and likely effects of such changes on their practice and on the learning of their students, as well as demanding different behaviours from each of the parties. This can involve teachers reshaping their own beliefs about what constitutes effective science teaching and learning, especially if their new practice differs from that of their colleagues in school (Cochran-Smith, 1994). Teachers are therefore challenged to justify not only to themselves but also to their students, colleagues and other interested parties as to why they are bringing in these new practices. As such, developing new practices is a risky business and one that will call on teacher time and effort to ensure that they are not only effective but seen as acceptable within the school context (Loucks-Horsely et al, 2003). Such developments frequently take place in environments where there are competing priorities for teacher time and development of practice (Harrison, 2005).

Finding 3: Constructing the portfolios provided further opportunity for reflection, discussion and learning for the teachers.

An essential task within the programmes was to introduce the idea of the portfolio so that teachers' understood the role and nature of the portfolio and its contribution to their professional learning, and had sufficient guidance about how to go about constructing a portfolio. This was achieved by focusing on features in each domain that indicated 'accomplished' practice, that is, practice that demonstrated an 
understanding of teaching and learning in that domain. Teachers were thus able to focus on evidence that showed their progress towards accomplishment in the domain in which they were working and so the processes that they engaged in took a more ipsative rather than comparative approach to their professional development. They did not compete with one another but rather focused on their own learning journeys, while at the same time often working collaboratively with peers to help them realize their progress towards accomplished teaching in that domain.

The notion of 'learning through reflection' is central to the use of portfolios for teacher development (Dinham \& Scott, 2003), and is a recognised feature of professional learning systems (e.g. Hoban, 2002, Loucks-Horsley et al 2003, Munby et al, 2000). The selection of pieces of evidence for the portfolio is an important first step towards reflecting on practice. For example, teachers can use resources they have developed, student outcomes, video material etc to reflect on the effectiveness of their practice and their own professional learning. Other researchers have shown that the process of reflection in portfolio construction can be enhanced through peer discussion and collaboration (Davis \& Honan 1998, Grant \& Huebner 1998, Lyons 1998, Shulman 1992). The provision of feedback, questions and different perspectives by peers and mentors can strengthen the portfolio development process through broadening the process of reflection, as Orland-Barak (2005) found when teachers became more dialogic as they collaborated.

\section{Conclusions and Implications}

This paper focuses on the design of CPD programmes and highlights the need for teacher reflection on their practices, beliefs and learning as an 'on-going' and vital 
part of the CPD programme. It starts to unpack some of the complexities involved in effective CPD programmes and focuses on how seeking and reporting on evidence of practice helps teachers reflect on, and develop their practice. As such it will provide messages that will be useful to CPD providers and those interested in teacher learning as well as provide a tool kit of activities within each domain designed to promote teacher learning and enhance practice.

The main findings were that the socio-cultural practice that was engaged in through the CPD programmes played an essential part in aiding teacher learning. The teachers needed to recognize good practice within a domain, make sense of its complexities and understand the effects and synergies of various aspects of practice as they came to find their own ways in establishing such practice. This approach was made possible by the programme designs, which gave allowance for collaborative activity and professional conversations, and the impetus derived from the collection, analysis and reflection on evidence. Such ways of working took considerable more time than had been envisaged at the start of the project as teachers needed to be involved in planning, actioning and evidencing their own practice as well as analyzing and reflecting on their practice and that of others. This has implications for CPD providers since such programmes are costly in both time and funding, but also because it signals strongly that teachers need strong support in the initial phases of an evidence-based approach and this needs to be factored into any new programme.

Providing the opportunity to set up an iterative cycle of planning, trialling and reflecting, where the essential features of scrutiny and guidance were effected in the trusting environment of 'like-minded' colleagues enabled teachers to overcome their own institutional hurdles to change. The processes involved in the evidence-based 
approach helped teachers build a portfolio, and, more importantly, encouraged them to undergo the change process from which their new practice evolved. The role of the portfolio was to provide a process of evidence collection, discussion and reflection that documented, supported and strengthened a teacher's changing practice. It fostered an agency of change which helped the teachers gradually transform their classroom practice within a specific domain.

The researchers from all six domains were experienced in working with teachers on CPD programmes prior to this research but their focus previously had been on producing activities to engage the teachers in understanding the ideas of the domain. The work on this project took the materials that researchers had already produced and developed the processes that aided teacher reflection and professional learning. It enabled the teachers to start to move from translating the ideas of the domain into practice to transforming their practice. It was not simply trying out some new ideas within their existing practice but a change in practice in which the new ideas drove their classroom approach. While the degree to which each teacher achieved this differed, it was clear that the CPD programmes had a marked affect on their practice as witnessed in their portfolio pieces, on video clips and in classroom observations.

The paper set reflects the varied and innovative ways in which the teacher development has been achieved. Experimenting with an evidence-based approach was aided by the cross-cultural element of this project. Working on a common approach from two different perspectives enabled us to see the commonalities within our data and so helped us unpick the essential elements from those that occurred through local or sample preferences. This helped us clarify both the teacher development side and 
research part of the project. The two country approach also allowed us to exchange ideas and discuss the research background, data and interpretations more broadly than we would have achieved working only with colleagues from similar backgrounds and institutions.

\section{References}

Adey, P. with Hewitt,,G., Hewitt, J. and Landau, N. (2004) The Professional Development of Teachers: Practice and Theory. London, Kluwer Academic Publishers

Ball, D.L. (2004). Professional development through records of instruction. Can be accessed at:

\section{http://www7.nationalacademies.org/mathteacherworkshop/ballbass1.pdf}

Ball, D. L. and Cohen, D.K. (1999). Developing practice, developing practionaires: Towards a practice-based theory of professional education. In L. Darling-Hammond and G Sykes (Eds.), Teaching as the learning profession (pp. 3-31). San Francisco, CA: Jossey-Bass.

Bell, B. and Gilbert, L. (1994). Teacher development as personal, professional, and social development. Teaching and Teacher Education. 10, 483-497.

Bell, B. \& Gilbert, J. (1996). Teacher Development: A Model from Science Education. London: Routledge Falmer.

Borko, H. and Putnam, R. (1996). Learning to teach. In D. Berliner and R. Calfee (Eds.), Handbook of educational psychology (pp. 673-708). New York: Macmillan. 
Borko, H. (2004). Professional development and teacher learning: Mapping the terrain. Educational Researchers, 33(8), 3-15.

Cordingley, P., Bell, M., Evans, D. \& Firth, A. (2005). The impact of collaborative CPD on classroom teaching and learning. Review: What do teacher impact data tell us about collaborative CPD? In: Research Evidence in Education Library. London: EPPI-Centre, Social Science Research Unit, Institute of Education, University of London.

Cochran-Smith, M. and Lytle, S.(1999) Teacher Learning in Communities. Review of Research in Education. Washington DC: American Educational Research Association.

Cuban, L (1998), "A tale of two schools", Education Week, Vol. 17 No.20, pp.28

Dillon, J., Osborne, J., Fairbrother, R. \& Kurina, L. (2000). A study into the professional views and needs of science teachers in primary and secondary schools in England. London: Kings College.

Davis and Honan (1998) Reflections on the Use of Teams to Support the Portfolio Process in N.Lyons (ed.) With Portfolio in Hand: Validating the New Professionalism. New York: Teachers College Press.

Dinham, S. \& Scott, C. (2003) Benefits to Teachers of the Professional Learning Portfolio: a case study. Teacher Development, 7 (2) 229-243. 
Grant, G.E. and Heubner, T.A. (1998) The Portfolio Question: The Power of SelfDirected Inquiry, in N.Lyons (ed.) With Portfolio in Hand: Validating the New Professionalism. New York: Teachers College Press.

Hoban, G. (2002) Teacher learning for educational change. Buckingham, Open University Press.

Guskey, T. and Huberman, M. (Eds). (1995).Professional development in Education: New Paradigms and Practices. New York: Teacher College Press

Harrison, C (2005) Teachers Development of Assessment for Learning: mapping teacher change. Journal of Teacher Development, 9 (2). pp 255-263

Hofstein, A., Carmi, M., and Ben-Zvi, R. (2003). The development of leadership among chemistry teachers in Israel. International Journal of Science and

Mathematics Education, 1, 36-65.

Hutchings, P. and Shulman, L.S. (1999). The scholarship of teaching - New elaborations, new developments. Change, 31 (5), 10-15

Joyce B. \& Showers, B. (1988) Student achievement through staff development. White Plains, NY: Longman.

Klenowski, V. (2002) Developing Portfolios for Learning and Assessment. London: RoutledgeFalmer. 
Lave, J., and Wenger, E. (1991), Situated Learning: Legitimate Peripheral Participation. New York: Cambridge University Press.

Loucks-Horsley, S., Love, N., Stiles, K, Mundry, S. \& Hewson, P. (2003) Designing Professional Development for Teachers of Science and Mathematics ( $2^{\text {nd }}$ Edition). Thousand Oaks, CA: Corwin Press Inc.

Loucks-Horsley, S., Hewoson, P., Love, N., and Stiles, K. E. (1998). Designing Professional development for teachers of science and mathematics. Thousand Oaks, CA: Crowin Press.

Lyons, N. (ed.) (1998) With Portfolio in Hand: Validating the New Professionalism. New York: Teachers College Press.

Magnusson, S., Krajcik, J., and Borko, H. (1999). Nature, sources and development of pedagogical content knowledge for science teaching. In J.Gess-Newsome and N.G. Lederman (Eds.), Pedagogical content knowledge and science education. (pp 95-132), Dordrecht: Kluwer Academic Publishers.

Marx, R. W., Freeman, J. K., Kracjik, J. S., and Blumenfeld, P. C. (1998).

Professional development of science teachers. In B. J. Fraser \& K. G. Tobin (Eds.), International handbook of science education. (pp. ). Dordrecht: Kluwer Academic Publishers.

Munby, H., Cunningham, M. \& Lock, C. (2000) School Science Culture: A case study of barriers to developing professional knowledge. Science Education, 84, 193-211. 
Orland-Barak, L. (2005) Lost in Translation: Mentors Learning to Participate in Competing Discources of Practice. Journal of Teacher Education, 56(4): pp 355 366.

Priestly, M. and Sime, D. (2005) Formative assessment for all: a whole school approach to pedagogic change. The Curriculum Journal, 16 (4), pp. 475 - 492.

Putnam, R. and Borko, H. (2000). What do new views of knowledge and thinking have to say about research on teacher learning? Educational Researchers, 29(1), 4-15.

Ruddock, J. (1991), Professional Development in School, Open University, Milton Keynes.

Scherz Z., Spektor-Levy, O., and Eylon, B. (2004). "Scientific Communication": An instructional program for high order learning skills and its impact on students' learning": Proceeding of the ESERA Conference 2003, Dordercht: Kluwer Academic Publishers.

Shulman, L. (1987).Knowledge and teaching: Foundation of the new reform, Harvard Educational Review, 57(1), 1-22.

Shulman, L. (1992) Portfolios in Teacher Education: A Component of Reflective Teacher Education, paper presented at the annual meeting of the American Educational Research Association, San Francisco. Shulman, L.S. \& Shulman, J.H. (2004) How and what teachers learn: a shifting perspective. Journal of Curriculum Studies 36 (2) pp257-271 
Turner-Bisset, R. (1999). The knowledge bases of the expert teacher. British Educational Research Journal. 25 (1). 39-55.

\begin{abstract}
Van Driel, J.H., Beijaard, D \& Verloop, N.(2001). Professional development and reform in science education: the role of teachers' practical knowledge. Journal of Research in Science Teaching. 38 (2), 137-158.
\end{abstract}

